index to 1 , species $A, B, C, D$ and $E$ then have the relative weights $1,1,1,1.5$ and 3 , respectively. This is clearly different from weighting all five species equally, although in this excessively simple example it is not too different from the extreme of weighting sister groups equally (giving relative weights $1,1,1,3$ and 6 to $\mathrm{A}, \mathrm{B}, \mathrm{C}, \mathrm{D}$ and $\mathrm{E}$ respectively).

This particular scheme of Vane-Wright et al. has the slight disadvantage that, for the values accorded individual species, it rests solely on topology, taking no account of how many lines branch from each node. A minor refinement, retaining the spirit of their ideas, is to count not simply the number of nodes between twig-tip and root, but rather the sum of the branches at all such nodes. In this scheme, the nodes labelled $\alpha, \beta, \gamma$ in the figure have 2, 2 and 3 branches respectively, and consequently we count 7 for $\mathrm{A}, \mathrm{B}$ and $\mathrm{C} ; 4$ for D, and 2 for $\mathrm{E}$. Taking these numbers to give inverse measures of taxonomic distinctness, as before, we arrive at the relative values of $1,1,1,1.75$ and 3.5 for $\mathrm{A}, \mathrm{B}, \mathrm{C}$, $\mathrm{D}$ and $\mathrm{E}$ respectively. The differences from Vane-Wright et al.'s scheme are small here, and disappear altogether in fully resolved trees, but can be significant in partially resolved hierarchies in which some branches are binary whereas others are multifoliate.

Returning to the tuatara, if all species are weighted equally, the two species represent only 0.03 per cent of all reptiles. At the opposite extreme - equal weight for all sister groups - they represent 50 per cent. Depending on how one approximates the complex topology of the hierarchical classification of all reptiles, I estimate that the scheme developed by Vane-Wright et al. implies that tuataras represent between 0.3 and 7 per cent of the taxonomic distinctness found among the 6,000 reptile species (and probably closer to the lower number).

Lifting our sights from species to faunal assemblies, suppose we wish to find, from some larger list, the minimal set of reserves that will include, say, every one of the 158 species of milkweed butterflies. In its simplest form, this is a version of the travelling-salesman problem ${ }^{2}$. Ackery and Vane-Wright ${ }^{4}$ have shown that, in practice, a good solution is obtained by examining a compendium of some 350 sample areas distributed around the globe, and noting the numbers of species (and patterns of endemism) in each area. They then work up a solution by first choosing the most species-rich region, which is the island of Sulawesi with 33 of the 158 (9 of which are endemic). Next comes the region with the highest remaining total, excluding the species already present in Sulawesi. And so on, always choosing the best region to compensate for species not yet incorporated.

In this way, Ackery and Vane-Wright find that a total of 31 reserves provides a critical set that embraces all species of milkweed butterflies. Although, as Vane-Wright et al. point out ${ }^{2}$, this simple method does not necessarily give the minimal set, it is a sensible and efficient method that is surely close to, if not exactly, optimal. A much more complex example of this kind is the recent assignment of priority-grades to different areas of Amazonia, according to measures of the richness of plant and animal species ${ }^{5}$.

The above-mentioned studies were essentially based on counting species. Were it not possible to acquire a range of reserves that included all the species in the designated group, the criterion would presumably be to maximize the attainable number. But if we weigh the species according to some measure of taxonomic distinctness, along the lines just developed, the answers can be significantly different. Vane-Wright et al. illustrate this by first using the topology of a current classification of the bumble-bees in the Bombus sibiricus group to assign indices of taxonomic distinctness to each of the 43 species in question, and then carrying out an analysis of priority areas among the 120 equal-area grid squares occupied by members of this group on a global map. By a simple species count, the top-ranking grid square centres on Ecuador, with 10 species (23 per cent of the total). But when taxonomic distinctness is taken into account, the top square lies in the Gansu area of China, containing 23 per cent of the total weighted scores for taxonomic distinctness, versus 15 per cent for the Ecuador-centred square.

All this work represents only the beginnings of what might be called the calculus of biodiversity. At very least, we need to combine quantitative measures of taxonomic distinctness with more familiar ecological considerations of abundance and geographical distribution ${ }^{6.7}$. Some may find it surprising that taxonomy, embodied in the hierarchial trees of systematists, stands alongside ecology in the emerging calculus. There should be no surprise. Without taxonomy to give shape to the bricks, and systematics to tell us how to put them together, the house of biological science is a meaningless jumble.

Robert M. May is in the Department of Zoology, University of Oxford, South Parks Road, Oxford OX1 3PS, UK.

1. Daugherty, C.H., Cree, A., Hay, J.M. \& Thompson, M.B. Nature 347, 177-179 (1990).

2. Vane-Wright, R.I., Humphries, C.J. \& Williams, P.H. Biological Conservation (submitted).

3. Atkinson, I. in Conservation for the Twenty-First Century (eds Western, D. \& Pearl, M.) 54-69 (Oxford University Press, Oxford, 1989)

4. Ackery, P.R. \& Vane-Wright, R.I. Milkweed Butterflies (British Museum (Natural History), London, 1984).

5. Kuliopulos, H. Science 248, 1305 (1990).

6. Rabinowitz, D., Cairns, S. \& Dillon, T. in Conservation Biology (ed. Soule, M.E.) 182-204 (Sinauer, Sunderiand, Mass., 1986).

7. Pagel, M.D., May, R.M. \& Collie, A.R. Am. Nat. (in the press).

\section{Tame twisters}

Solar energy, says Daedalus, is usually too dilute and diffuse to be harnessed easily. A tornado, however, gathers it from a very wide area. The Sun-heated land of the region warms the air just above it; this lowlying stratum of warm air, seeking to rise, forms a large convection cell with a small central rising column. All the heat energy of the indrawn air, and its angular momentum from the Earth's rotation, is concentrated in this narrow updraught, which spins and rises violently. Daedalus is now devising a 'tame tornado', capable of generating useful power.

A wild tornado, of course, wanders destructively about. Daedalus's tame one will be safely anchored to one spot. Its central rising column will be defined and located by a tall chimney. At first the engineering problems looked daunting. Some sort of vast cooling tower seemed called for, many hundreds of metres tall, supported clear of the ground to admit radially inrushing air, and strong enough to withstand its violent spin and upflow inside. But Daedalus then recalled the airport windsock, that simple fabric sleeve kept extended and inflated by the wind blowing through it. So his tame tornado is now simply an outsize vertical windsock. Like its airport counterpart, its inlet will be kept circular by attachment to a rigid hoop, anchored by cables to a single axial point. The air rising within it will keep it inflated and vertically extended; the cable anchorage will stop it blowing away upwards, but will allow hoop and sock to spin freely about their vertical axis. Internal 'sails' on the windsock will act as turbine blades driven by the spinning air column within. Thus the whole windsock will spin with the twisting updraught inside it, delivering useful power to a generator attached to the anchorage.

The tame tornado will be activated whenever the weather seems promising. The process will be something like launching a big fire balloon. The windsock will be inflated by a powerful draught of warm air, blown by big ducted fans and heated by propane burners, until natural tornado convection takes over and the windsock is self-sustaining. Thereafter, the installation will run for days or weeks on end, capturing much of the solar energy over a wide radius of countryside. Even at night, the Sun-heated soil will keep the convection cell in being.

A tame tornado will handle much less energy than the wild variety, and should be a relatively mild and safe device. Nonetheless, a grid of them spread across tornado country would usefully steal the energy needed by wild tornadoes. Any tornado approaching the grid would find itself rapidly starved of power, and would soon collapse exhausted. 